\title{
PURIFICACIÓN DE UNA ENZIMA PROTEOLÍTICA DEL VENENO DE Bothrops brazili Y ESTUDIO DE SU ACTIVIDAD SOBRE FIBRINÓGENO
}

\author{
PURIFICATION OF A PROTEOLYTIC ENZYME FROM THE VENOM OF Bothrops brazili \\ SNAKE AND STUDY OF ITS ACTIVITY ON FIBRINOGEN
}

\author{
María Azañero, Enrique Escobar y Armando Yarlequé*
}

\section{RESUMEN}

Se ha aislado una enzima proteolítica del veneno de la serpiente peruana Bothrops brazili, por cromatografia en Sephadex G-100 y CM-Sephadex C-50, con buffer acetato de amonio 0,05M pH 7,0. La enzima fue purificada 3,2 veces con un rendimiento de $52,5 \%$ y el peso molecular calculado por filtración en gel fue de 18000 , mientras que la PAGE-SDS permitió observar una sola banda proteica de 22000 daltons en condiciones reductoras y de 20300 daltons en condiciones no reductoras, determinándose que la enzima es de una sola cadena polipeptídica con al menos un enlace disulfuro.

La enzima hidroliza fibrinógeno, fibrina, caseina y albúmina, pero no hemoglobina ni mioglobina. Por su acción sobre el fibrinógeno, es una $A \alpha$-fibrinogenasa ya que hidroliza primero la cadena A $\alpha$ del fibrinógeno y luego la cadena B $\beta$. Esta actividad es inhibida por EDTA pero no por PMSF, TLCK, iodoacetato y pepstatin, indicando que se trata de una metaloproteinasa; sin embargo, los iones Ca"*, $\mathrm{Mg} *$ y $\mathrm{Zn}^{*}$ no restablecen la actividad. Finaimente, la enzima es estable hasta los $45^{\circ} \mathrm{C}$ y en su acción sobre fibrina, la hidrólisis se da preferencialmente sobre la cadena $\alpha$.

Palabras clave: Enzima, fibrinogenasa, veneno, Bothrops brazili

\section{ABSTRACT}

A proteolitic enzyme was purified from Bothrops brazili peruvian snake venom using Sephadex G100 followed by $\mathrm{CM}$-Sephadex $\mathrm{C}-50$, in both two cases with $0.05 \mathrm{M}$ ammonium acetate $\mathrm{pH} 7,0$. The enzyme was purified 3,2 fold with $52,5 \%$ of yield and by gel filtration the enzyme showed 18000 of molecular weight, while the PAGE-S.DS showed only one protein band of 22000 in the presence of mercaptoethanol and 20300 under nonreducing conditions which suggests that the enzyme has a single polypeptide chain with disulfide bond.

The enzyme hydrolizes flbrinogen, fibrin, casein and albumin, but not hemoglobin and mioglobin. The enzyme is a Ac-fibrinogenase because preferentially hydrolizes the $A \alpha$ chain of the fibrinogen molecule. This activity is inhibited by EDTA but not by PMSF, TLCK, iodoacetate and pepstatin, suggests that is a metalloproteinase, however the lons $\mathrm{Ca}++, \mathrm{Mg}++$ and $\mathrm{Zn++}$ cannot reactivate the inhibition by EDTA. Finally the enzyme is stable up to $45^{\circ} \mathrm{C}$ and in its effect on fibrin the enzyme is to attack $\alpha$ chain rapidly.

Key words: Enzyme, fibrinogenase, venom, Bothrops brazili

\section{INTRODUCCIÓN}

La disolución de coágụlos de fibrina por la enzima plasmina es un proceso esencial para impedir la formación de trombos y mantener la fluidez de la sangre. Por los años 30 se descubrió que la estreptoquinasa, una enzima liberada por la bacteria Streprococcus, genera

\footnotetext{
- Laboratorio de Biologia Molecular. Facultad de Ciencias Biologicas, UNMSTM.
}

plasmina a partir de plasminógeno y por lo tanto disuelve los coágulos de sangre (Tillet \& Gamer, 1933). Actualmente, esta proteína se usa ampliamente en el tratamiento de ciertas enfermedades trombóticas tales como el infarto agudo del miocardio, embolia pulmonar y trombosis de venas profundas (Goa et al., 1990). Sin embargo, el uso de estreptoquinasa y otros agentes trombolíticos puede ocasionar diversos efectos colaterales, perjudiciales al 
paciente, por lo que se hace necesario obtener nuevos productos trombolíticos que sean tan efectivos como inocuos para el paciente. Esto implica la posibilidad de usar enzimas capaces de convertir el plasminógeno en plasmina o que hidrolicen directamente la fibrina $y / o$ el fibrinógeno, previniendo así la formación de coágulos de fibrina.

En este sentido, los venenos de serpientes, particularmente de la familia Viperidae, son ricos en enzimas proteolíticas capaces de hidrolizar algunas proteínas plasmáticas como fibrinógeno y fibrina. Desde la perspectiva clínica, estas enzimas tienen una potencial utilidad para disolver coágulos de sangre formados durante una patología trombótica (Markland, 1988).

$B$. brazili es una serpiente de nuestro país que habita en la región del Alto Marañon y que produce abundante veneno, hasta $4 \mathrm{ml}$ en cada mordedura (Meneses, 1974). En este veneno recientemente se han aislado y caracterizado las enzimas fosfolipasa (Zeballos et al., 1999) y L-aminoácido oxidasa (Solís et al., 1999), pero ya en 1996 se reportó la existencia de una enzima proteolítica con acción sobre caseína y fibrinógeno (Escobar et al, 1996); sin embargo, este último aspecto sólo fue abordado muy tangencialmente, por lo que en este trabajo decidimos estudiar detalladamente la acción sobre fibrinógeno, a fin de esclarecer el rol de la enzima durante el envenenamiento y evaluar sus posibilidades como agente trombolítico.

\section{MATERIAL Y MÉTODOS}

Veneno de serpiente. El veneno de $B$. brazili fue proporcionado por el serpentario Oswaldo Meneses del Museo de Historia Natural de la Universidad Nacional Mayor de San Marcos, donde especimenes procedentes del Alto Marañón son mantenidos en cautiverio a $28^{\circ} \mathrm{C}$. El veneno extraído por presión manual de las glándulas fue liofilizado y conservado a $-8^{\circ} \mathrm{C}$.
Cuantificación de proteína. Durante la purificación de la enzima, la proteína se determinó por la absorción de luz ultravioleta a 280 nm (Warburg \& Christian, 1941), mientras que en la enzima purificada, la cantidad de proteína se determinó por el método de Lowry et al. (1951).

Evaluación de la pureza y determinación del peso molecular. La pureza y el peso molecular de la enzima fueron determinados por electroforesis en gel de poliacrilamida con dodecil sulfato de sodio (PAGE-SDS), utilizando como colorante azul de coomassie 0,1\% (Weber \& Osborn, 1969). Adicionalmente el peso molecular también fue calculado por cromatografía de filtración en una columna de Sephadex G-100 (Andrews, 1964).

Purificación de la enzima. $50 \mathrm{mg}$ de veneno fueron disueltos en $1 \mathrm{ml}$ de buffer acetato de amonio 0,05M a pH 7,0 y luego de eliminar los restos insolubles por centrifugación a 1500 $x g$ por 15 minutos, $0,95 \mathrm{ml}$ del sobrenadante se aplicaron a una columna de Sephadex G$100(1,2 \times 44,3 \mathrm{~cm})$, equilibrada con buffer acetato de amonio 0,05M a pH 7,0. En las fracciones colectadas se midió la cantidad de proteína y la actividad caseinolítica. Las fracciones con mayor actividad fueron reunidas $y$ aplicadas a una columna de CM-Sephadex C$50(1,2 \times 17,5 \mathrm{~cm})$, equilibrada con el mismo buffer. Las proteínas retenidas en la columna fueron eluidas con el buffer de corrida conteniendo sucesivamente $\mathrm{NaCl} 0,05 \mathrm{M}, 0,3 \mathrm{M}$ y $0,6 \mathrm{M}$. En cada fracción igualmente se determinó la cantidad de proteina y la actividad caseinolítica. En ambos sistemas el flujo fue de $5 \mathrm{ml} / \mathrm{h}$ y se trabajo a temperatura ambiente.

Actividad caseinolítica. Durante la purificación de la enzima, su actividad proteolítica se midió sobre caseína, para lo cual se incubó $1,5 \mathrm{~m}$ l de caseína $2 \%$ disuelta en buffer Tris $\mathrm{HCl} 0,2 \mathrm{M} \mathrm{pH} 7,5$, con $0,4 \mathrm{ml}$ de agua destilada y $0,1 \mathrm{ml}$ de la enzimá, durante 15 minutos a 
$37^{\circ} \mathrm{C}$. La reacción se detuvo con $1,5 \mathrm{ml}$ de ácido tricloro acético $0,44 \mathrm{M}$ en frío y los productos ácidos solubles obtenidos por centrifugación a $1500 \mathrm{xg}$ durante 15 minutos, fueron leídos a $280 \mathrm{~nm}$. Para calcular la actividad específica los valores de D. O. a $280 \mathrm{~nm}$ fueron convertidos a $\mu \mathrm{g}$ de L-tirosina, y expresados como unidades por mg de proteína (una unidad equivale a la liberación de $1 \mu \mathrm{g}$ de L-tirosina por minuto) (Takahashi \& Ohsaka, 1970).

Para los ensayos que a continuación se describen se empleó la enzima purificada a una concentración de $0,4 \mathrm{mg} / \mathrm{ml}$ (determinada por el método de Lowry).

\section{Acción proteolítica sobre fibrinógeno.} La actividad sobre fibrinógeno se midió incubando a $37^{\circ} \mathrm{C}, 0,8 \mathrm{ml}$ de fibrinógeno bovino 5 $\mathrm{mg} / \mathrm{ml}$, disuelto en buffer Tris- $\mathrm{HCl} 0,05 \mathrm{pH} 7,5$, y $40 \mu \mathrm{l}$ de la enzima purificada. A los 1, 3, 5, $10,20,30,60$ y 120 minutos se tomaron $80 \mu 1$ del incubado para su análisis por PAGE- SDS.

Efecto de algunos inhibidores de proteasas. Se evaluó el efecto del fenil metil sulfonil fluoruro (PMSF) $4 \mathrm{mM}$, tosyl lisil clorometil cetona (TLCK) $3 \mathrm{mM}$, pepstatin 3.6 $\mathrm{mM}$, iodoacetato $6 \mathrm{mM}$, etilen diamino tetra acético (EDTA) 1,5 mM y mercaptoetanol 20 $\mathrm{mM}$. En cada caso se preincubó $15 \mu \mathrm{l}$ de la enzima con $15 \mu \mathrm{l}$ del reactivo a $37^{\circ} \mathrm{C}$ durante 15 minutos y luego se midió la actividad sobre fibrinógeno con $20 \mu \mathrm{l}$ del incubado. La reacción se evaluó por PAGE-SDS.

Acción de iones metálicos. También se prob6 el efecto del calcio, magnesio y zinc bajo la forma de cloruros, sobre la enzima tratada con EDTA. Para estó, $15 \mu \mathrm{l}$ de la enzima se mezclaron con $15 \mu$ de EDTA $1,5 \mathrm{mM}$ durante 15 minutos a $37^{\circ} \mathrm{C}$ y luego se agrego por separado, $10 \mu \mathrm{l}$ del ion respectivo a concentraciones de 3 y $6 \mathrm{mM}$, incubándose a $37^{\circ} \mathrm{C}$ por 15 minutos más. Finalmente se probó y analizó la actividad fibrinogenolítica por PAGESDS.
Termoestabilidad "La termoestabilidad de la enzima se determino incubando a diferentes temperaturas $(37,45,55,65,75,85$ y $95^{\circ} \mathrm{C}$ ), alícuotas de $20 \mu \mathrm{l}$ de la enzima. Luego de 15 minutos se enfrió rápidamente a $4{ }^{\circ} \mathrm{C}$ por 3 minutos y se midió la actividad sobre fibrinógeno con $10 \mu l$ de cada muestra. El análisis se hizo por PAGE-SDS.

Acción sobre otras proteínas. La actividad fibrinolítica fue determinada sobre coágulos de fibrina, formados a partir de $0,2 \mathrm{ml}$ de fibrinogeno $5 \mathrm{mg} / \mathrm{ml}$ y $10 \mu \mathrm{l}$ de trombina humana $50 \mathrm{U} / \mathrm{ml}$ incubados a $37{ }^{\circ} \mathrm{C}$ por 30 minutos. A estos coágulos se añadió $10 \mu$ de la enzima y se incubó a $37^{\circ} \mathrm{C}$. A los $5,10,20$, 30,60 y 120 minutos se midio la actividad fibrinolítica por PAGE- SDS. Esta actividad también se evaluó por el método de Astrup y Mulertz (1952), observando directamente la disolución de los coágulos, con $10 \mu \mathrm{l}$ de la enzima, a intervalos de 30 minutos durante 3 horas.

También se evaluó por PAGE-SDS la probable acción proteolítica de la enzima sobre albúmina $4 \mathrm{mg} / \mathrm{ml}$, hemoglobina $2 \mathrm{mg} / \mathrm{ml}$, mioglobina $12 \mathrm{mg} / \mathrm{ml}$ y caseína $8 \mathrm{mg} / \mathrm{ml}$, disueltas en buffer Tris-HCl 0,05M a pH 7,5. La actividad se probó con $10 \mu 1$ de la enzima a $37^{\circ} \mathrm{C}$ durante 15 minutos.

\section{RESULTADOS Y DISCUSIÓN}

Purificación de la enzima. En el primer paso de purificación sobre Sephadex G-100 el veneno crudo fue fraccionado en 3 picos de proteína, y se encontró la mạyor actividad caseinolítica en la porción ascendente del segundo pico (Fig. 1). En esta etapa la enzima fue purificada 1,3 veces y con un rendimiento de $65,1 \%$. Durante el segundo paso de purificacion en CM-Sephadex C-50 a pH 7, un pequeño pico de protefna, sin actividad proteolítica, fue eluido directamente, mientras que el resto de proteína interactu6 con el gel, inclusive después de: añadir $\mathrm{NaCl} 0,05 \mathrm{M}$ al buffer de elución. Al aumentarse la concen- 


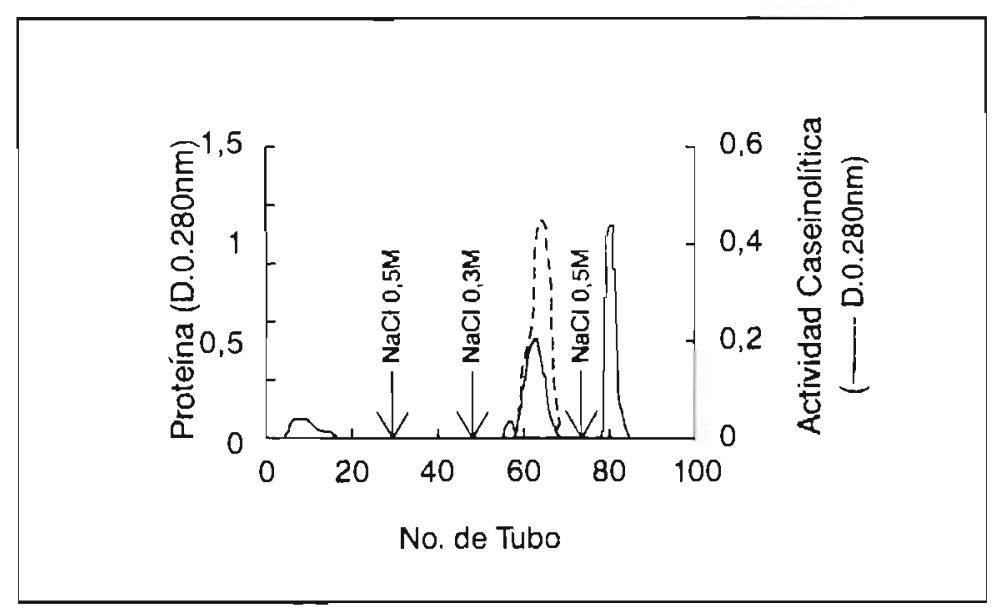

Figura 2. Purificación de la enzima proteolítica en $\mathrm{CM}$ Sephadex $\mathrm{C}-50$ a pH 7. En este intercambiador catiónico, la proteasa quedó ligada al gel y fue eluida luego de incorporar al buffer de corrida $\mathrm{NaCl} 0,3 \mathrm{M}$.

Tabla I. RESUMEN DEL PROCESO DE PURIFICACIÓN

\begin{tabular}{lccccc}
\hline ETAPA & Proteína (mg) & $\begin{array}{c}\text { Actividad } \\
\text { Específica }\end{array}$ & $\begin{array}{c}\text { Unidades Totales } \\
\text { de Actividad }\end{array}$ & Purificación & $\begin{array}{c}\text { Rendimiento } \\
(\%)\end{array}$ \\
\hline Crudo & 31,60 & 0,92 & 29,072 & 1,0 & 100,0 \\
Sephadex G-100 & 16,16 & 1,19 & 18,926 & 1,3 & 65,1 \\
CMSephadexC-500 & 4,55 & 2,94 & 15,263 & 3,2 & 52,5 \\
\hline
\end{tabular}
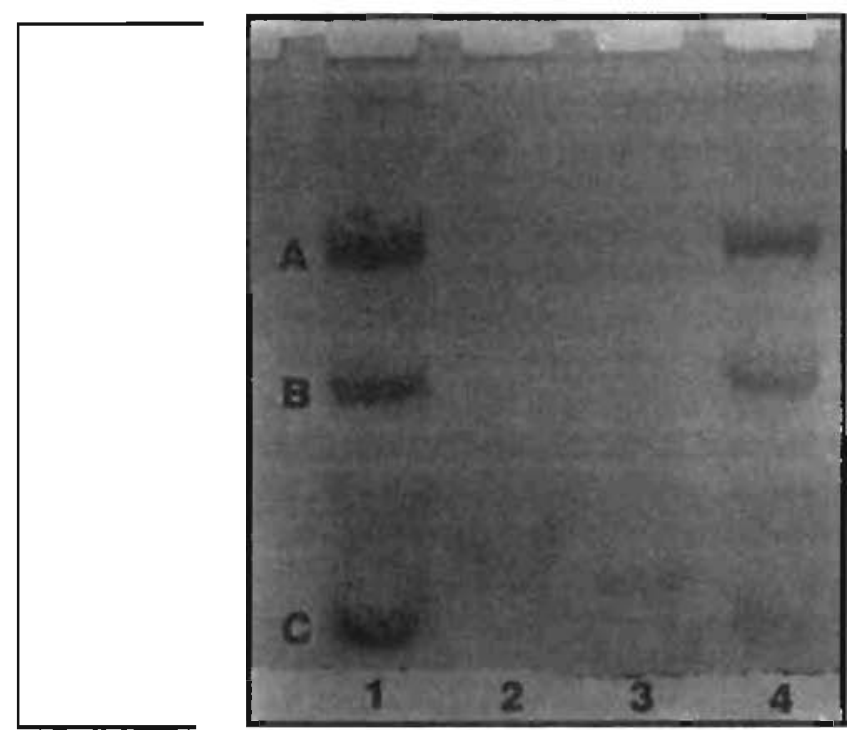

Figura 3. PAGE-SDS de la proteasa aislada del veneno de $B$. brazili. En los carriles 1 y 4 se observan los estándares de peso molecular: albúmina $(66 \mathrm{KDa})$, ovoalbúmina $(45 \mathrm{KDa})$ y lisozima $(14,3 \mathrm{KDa})$. En los carriles 2 y 3 se muestran la enzima reducida (22KDa) y no reducida $(20,3 \mathrm{KDa})$ respectivamente. 


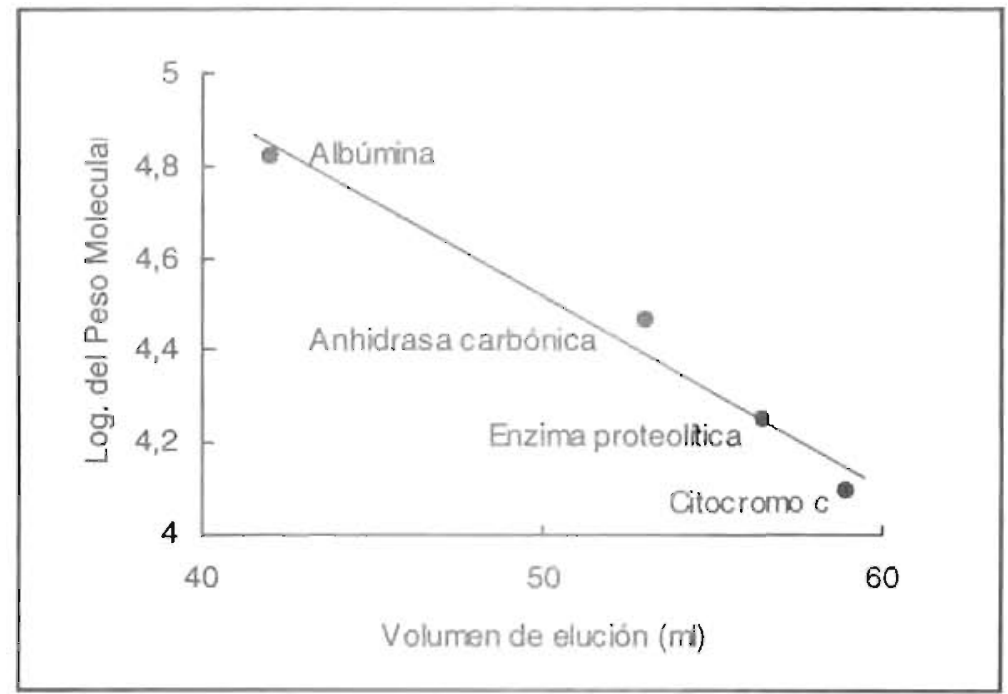

Figura 4. Determinación del peso molecular por cromatografia de filtración en Sephadex G-100. Usando albumina (66KDa), anhidrasa carbónica (29KDa) y citocromo c (12,4KDa), como estándares, se calculó un peso molecular de 18KDa para la enzima proteolítica

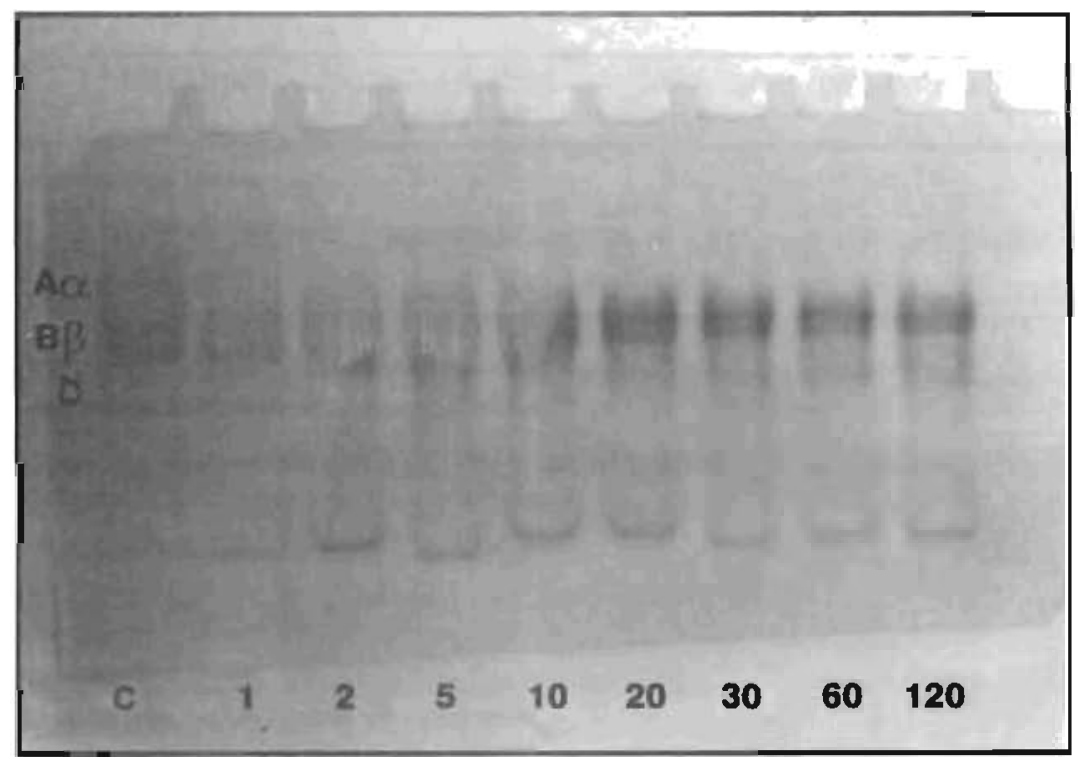

Figura 5. Evaluación por PAGE-SDS de la hidrólisis de fibrinógeno, EI patrón de fibrinógeno (C) fue modificado por la enzima desde el primer minuro de incubación.

ran \& Geren, 1981) y Lachesis muta (Escobar et al., 1992).

La función de estas fibrinogenasas, durante el envenenamiento, es retardar o anular la capacidad de coagulación del fibrinógeno atacando de manera preferencial la cadena $A \alpha$ y luego la cadena B $\beta$. De esta manera estos venenos producen una drástica alteración de la coagulación sanguínea debido a la desfibrinogenación que producen (Gutiérrez et al., 1982; Gutiérrez \& Bolaños , 1980). 
Termoestabilidad. Según el patrón de digestión del fibrinógeno mostrado en la Fig. 6 , se encontró que la enzima es termoestable hasta los $45^{\circ} \mathrm{C}$, y es inaclivada a partir de los $55^{\circ} \mathrm{C}$. Es sabido que mientras menor es el peso molecular de una proteína y mayor la cantidad de enlaces disulfuro, la proteína posee gran termoestabilidad. En el caso de la proteína en estudio, esta tiene bajo peso molecular, por lo que su gran sensibilidad al calor podría deberse a que tiene pocos enlaces disulfuro.

Una fibrinogenasa del veneno de Cerastes cerastes es estable hasta los $55^{\circ} \mathrm{C}$ (Daoud et al., 1987), mientras que la fibrinogenasa de L. muta tolera temperaturias de hasta $60^{\circ} \mathrm{C}$ (Escobar et al., 1992).

Efecto de algunos inhibidores de proteasas. De todos los inhibidores ensayados, sólo el EDTA produjo una completa inhibición de la actividad enzimática, lo cual significa que la proteasa en estudio es una metalo proteinasa. Esto coincide ampliamente con lo reportado para otras $A \alpha$-fibrinogenasas (Escobar et al., 1992; Markland et al., 1988; Evans, 1984; Tanizaki et al., 1989)
Por otro lado, ya que la actividad no fue afectada por PMSF, ácido iodoacético y TLCK, se puede deducir que la enzima no tiene serina, cisteina e histidina en su centro activo. En relación al pepstatin, éste se comportó como un inhibidor de la actividad; sin embargo, esta inhibición no se consideró concluyente, ya que el disolvente del pepstatin, el metanol, tambiên produjo inhibiciôn (Fig. 7).

También resulta interesante interpretar el hecho de que el mercaptoctanol no haya ejercido ningún efecto en là actividad enzimática, pues de los resultados sobre el peso molecular y la termoestabilidad, se dedujo que la enzima no debía tener muchos enlaces disulfuros pero si por lo menos uno, por lo que se deduce que Éstos no deben ser esenciales para mantener su función.

Efecto de algunos iones metálicos. De los resultados obtenidos en esta prueba, se ha determinado que la actividad de la enzima tratada con EDTA, no es restituida por calcio, magnesio o zinc, a concentraciones finales de 0,75 y 1,5 mM (Fig. 8).

El resultado encontrado por nosotros puede tener 2 explicaciones. Por un lado, la es-

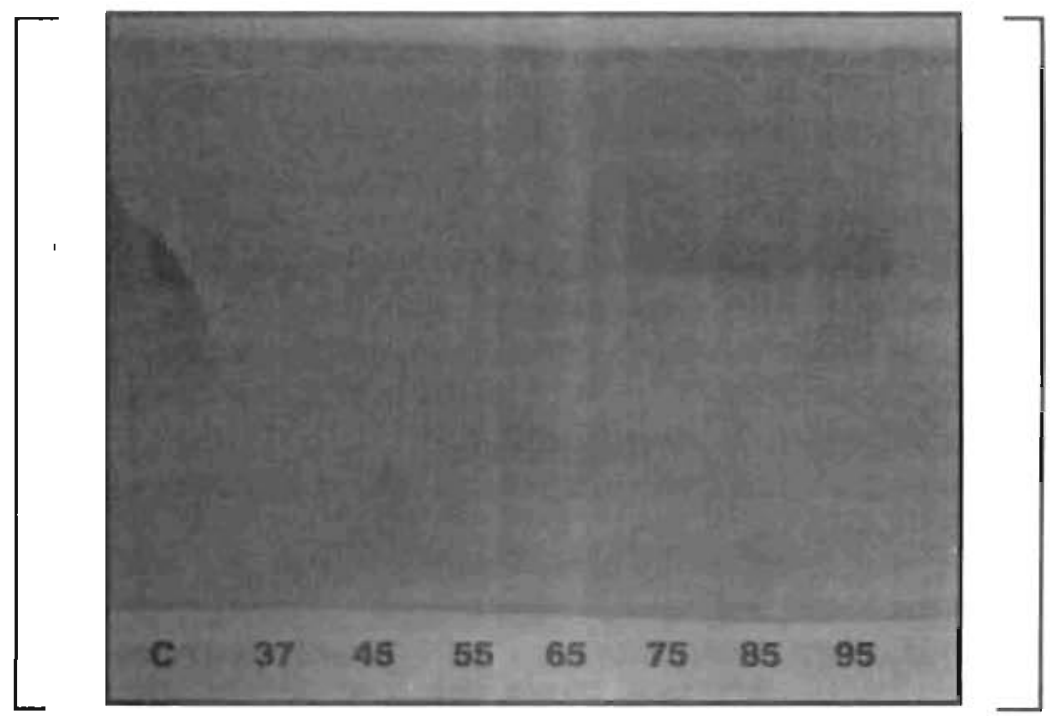

Figura 6. Termoestabilidad de la enzima. La actividad sobre fibrinógeno fue medida luego de preincubar la enzima a las temperaturas indicadas durante 15 minutos. 


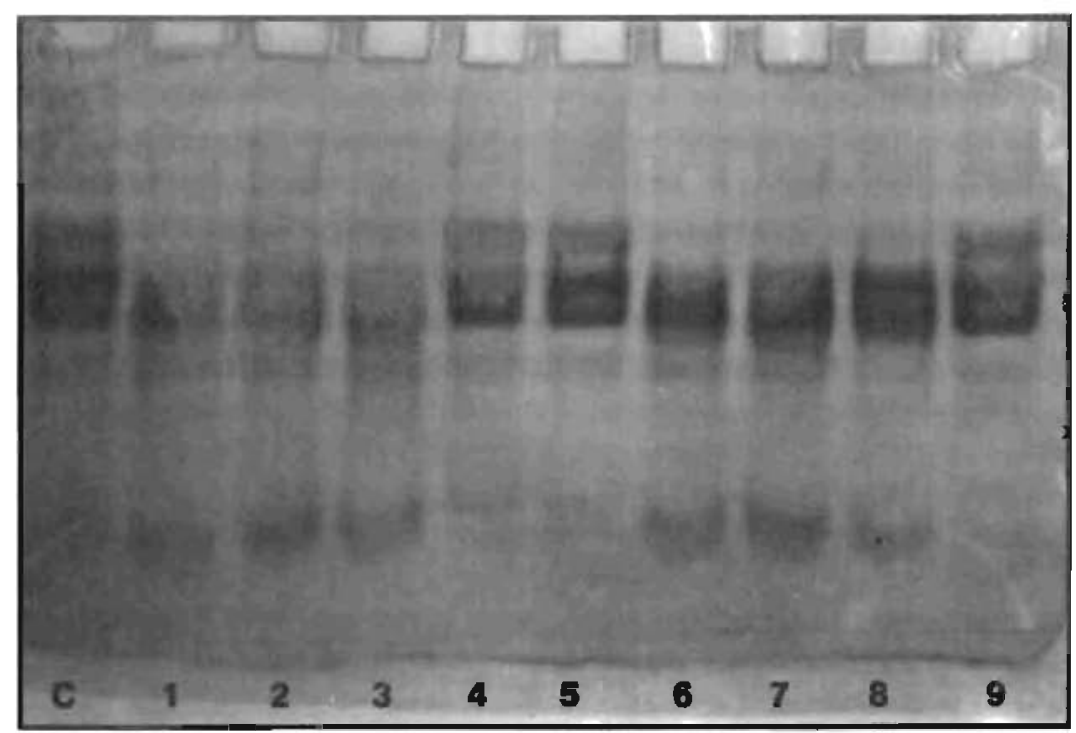

Figura 7. Efecto de algunos inhibidores de proteasas. La actividad sobre el fibrinógeno fue evaluada luego de preincubar la enzima con PMSF (2), iodoacetato (3), EDTA (4), pepstatin (5), TLCK (6), mercaptoetanol (7), etanol (8) y metanol (9). (C) corresponde al control de fibrinógeno y (1) a la actividad de la enzima sin tratamiento.

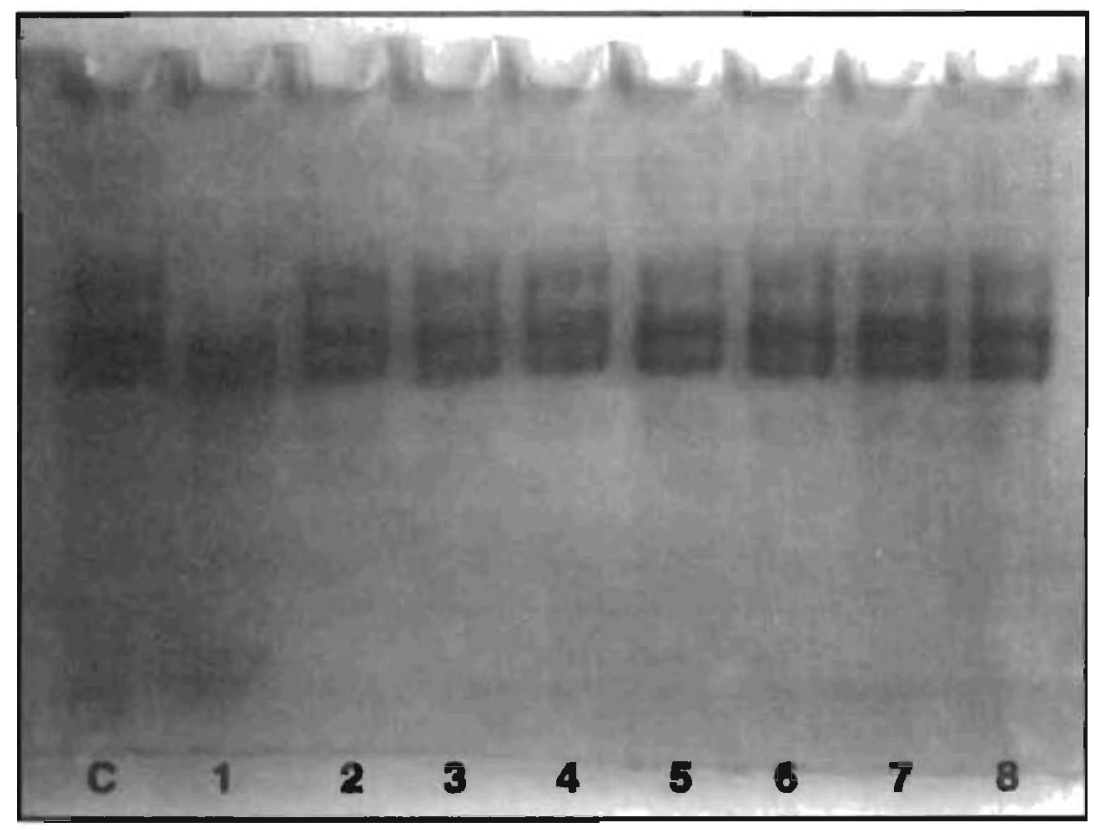

FIgura 8. Efecto del calcio, magnesio y zinc sobre la enzima tratada con EDTA. (C) control de fibrinógeno, (1) actividad de la enzima sin tratamiento, (2) actividad de la enzima tratada con EDTA, (3) y (4) efecto del Ca**0,75 y $1,5 \mathrm{mM},(5)$ y (6) efecto del $\mathrm{Mg}^{\star}+0,75$ y $1,5 \mathrm{mM},(7)$ y (8) efecto del $\mathrm{Zn}^{*} 0,75$ y $1,5 \mathrm{mM}$. 
tructura de la enzima tratada con EDTA poUría haber sido alterada drásticamente de modo que la inhibición resulta irreversible; y por otro lado, podría deberse a que el metal ligado a la enzima sea diferente de los utilizados. Algo similar se ha encontrado con la proteasa J del veneno de $B$. jararaca, la cual es irreversiblemente inactivada por EDTA y o-fenantrolina (Tanizakier al., 1989). Sin embargo, en otros casos la actividad de la enzima inhibida por EDTA puede ser restablecida por $\mathrm{Zn}^{+4}$ como en el caso de $L$. muta o por $\mathrm{Ca}^{++}$, como en el caso de V. lebetina (Escobar et al., 1992; Gasmi et al., 1991).

Acción sobre otras proteínas. La acción proteolítica sobre coágulos de fibrina, evaluada por PAGE-SDS, se eviđenció desde los 5 minutos sobre la cadena $\alpha$, mientras que a partir de los 20 minutos esta acción se extendiỏ a la cadena $\beta$ (Fig. 9). Cuando la actividad fibrinolítica se evaluó por el método de Asțup y Mulertz, fue posible observar una progresiva disolución del coágulo desde los 30 minutos, que se hizo mucho más evidente a partir de las 2 horas (Fig. 10).
Asimismo, la enzima mostró tener una elevada actividad hidrolítica sobre albúmina bovina, evidenciándose una lisis completa de ésta, mediante la formación de diferentes productos de menor peso molecular; asimismo se observó una actividad muy similar sobre caseína. A diferencia de lo anterior, no se evidenció ninguna alteración en los patrones electroforéticos de hemoglobina y mioglobina. En todos los carriles donde se colocó la proteína mas la enzima se observó una tenue banda correspondiente a la enzima, semejante a la presentada en el carril control (Fig. 11).

El hecho de que la enzimá también hidrolice fibrina permite denominarla enzima fibrino(geno)lítica, es decir, con capacidad de digerir tanto fibrinógeno cono fíbrina. De este modo, durante el envenenamiento, la actividad de esta enzima estaría involucrada no soio en la destrucción de fibrinógeno sino también en la hidrólisis de microcoágulos formados pocas horas después de la mordedura y posteriormente a la coagulación intravascular diseminada (Escobaret al., 1992). Por otro lado, la actividad fibrinolítica de la enzima, bajo las

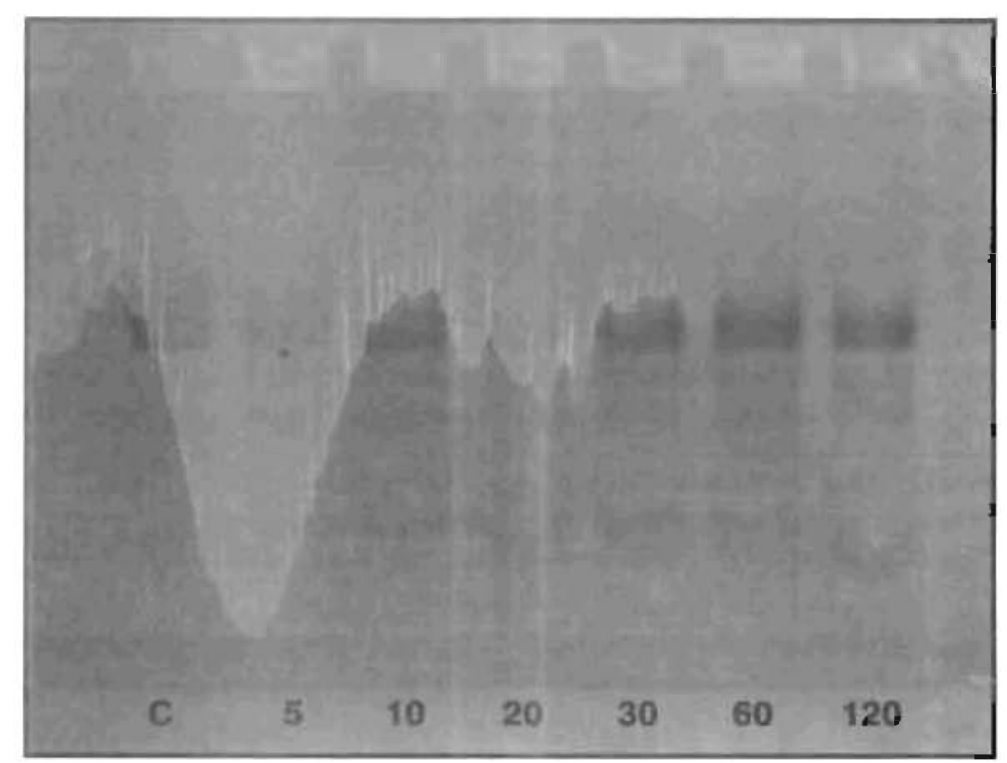

Figura 9. Evaluación por PAGE-SDS de la actividad de la enzima sobre fibrina. El patrón electroforético de la fibrina (c) fue modificado por acción de la proteasa desde los 5 minutos de incubación. 


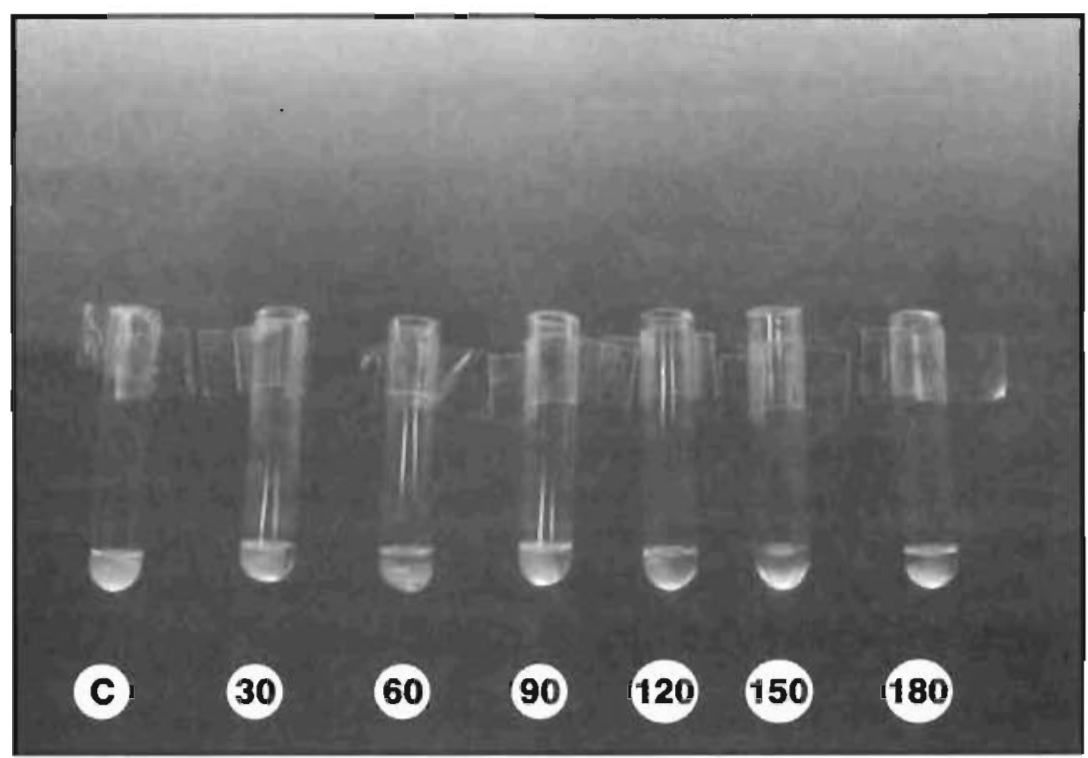

Figura 10. Evaluación de la actividad fibrinolítica por el método de Astrup y Mulertz.

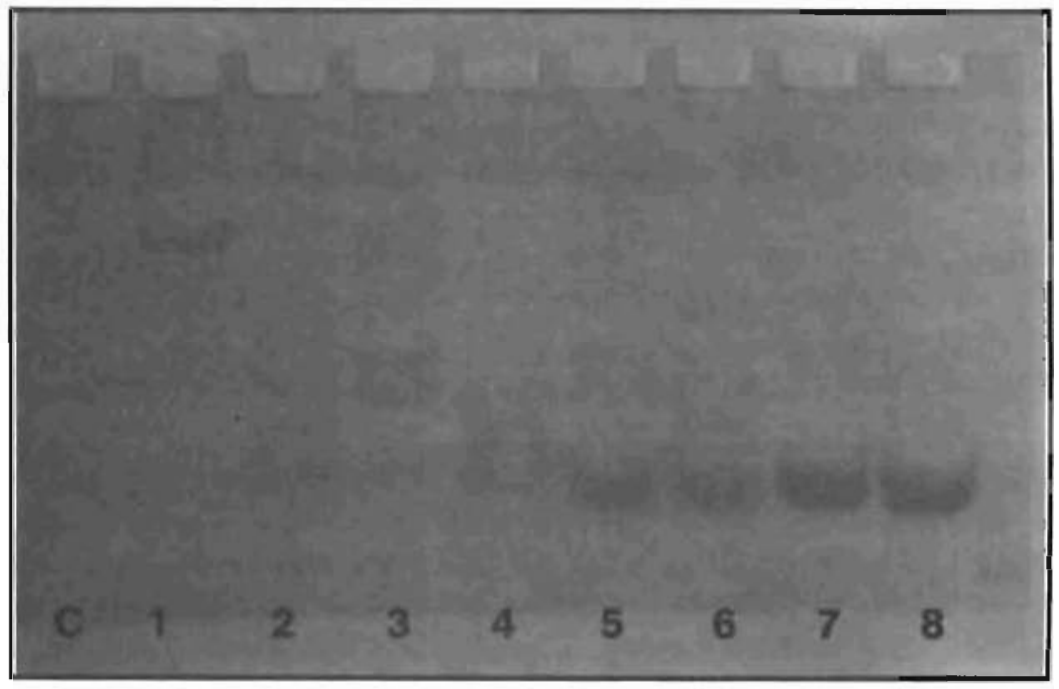

Figura 11. Actividad proteolitica sobre otras proteinas. En los carriles 1. 3,5 y 7 se muestran los controles de albúmina, caseina, hemoglobina y mioglobina respectivamente. Los carriles 2, 4, 6 y 8 corresponden a la actividad de la enzima sobre caseína, hemoglobina y mioglobina respectivamente, mientras que (c) es el control de la enzima.

condiciones en las que se ha determinado, indica que es de acciôn directa al igual que otras fibrinogenasas como la Bitis gabonica (Forbes et al., 1969) y la de A. C. contortrix (Herzig et al., 1970). Otras proteasas que también digieren coágulos de fibrina actúan de un modo indirecto, vía conversión de plasminógeno en plasmina tal como se ha reportado en los venenos de Crotalus atrox y C. adamanteus (Budzynsky et al., 1984; Budzynsky et al., 1988). Este modo de acción indirecto, en el caso de la enzima en estudio, no ha sido verificado. 
Por otro lado. la fuerte actividad de la enzima sobre albúmina indicarían que esta proteasa no es totalmente específica en su acción sobre fibrinógeno y/o fibrina, por lo que durante el envenenamiento esta proteasa tendría una participación muy activa. Sin embargo, su acción proteolítica sobre albúmina constituiría una desventaja desde el punto de vista de la posibilidad de su aplicación como agente trombolítico.

\section{AGRADECIMIENTO}

Los autores agradecen a la IFS de Suecia por su apoyo financiero para esta investigación.

\section{LITERATURA CITADA}

Andrews, P. 1964. The gel filtration behaviour of proteins related to their molecular weights over a wide range. Biochem. 5 (96): 595.

Astrup, T. and Mullertz, S. 1952. The fibrin plate method for estimating of fibrinolytic activity. Archs Biochem. Biophys. 40: 346.

Budzynski. A., Pandya, B., Rubin, R., Brizuela, B., Soszka, T. and Steward, G. 1984. Fibrinogenolytic afibrinogenemia after envenomation by Western diamondback rattlesnake (Crotalus atrox). Blood 63: 1

Budzynski, A., Kirshbaum, N. and Reczkowski, R. 1988. Secretion of celular plasminogen activators upon stimulation of Crotalinae snake venoms. In: Hemostasis and Animal Venoms. Pirkle and Markland (eds.). Marcell Dekker. New York. p. 191.

Doolittle, R. 1981. Fibrinogen and fibrin. Sci. Am. 245: 126

Escobar, L., Rodríguez, E. and Yarlequé, A. 1992. Isolation and partial characterization of a fibrinogenase from the venom of the peruvian bushmaster snake Lachesis mula. Recent advances in toxinology research. P. Gopalakrishnakone and C. K. Tan (eds.). Vol. I pp. 421-430.

Escobar, E., Rodríguez, E. y Yarlequé, A. 1996. Purificación y caracterización parcial de una proteasa del veneno de Bothrops brazili. Libro de resúmenes $\mathrm{V}$ Reunión Científica ICBAR, UNMSM, p. 56.

Evans, H. 1984. Purification and properties of a fibrinogenase from of venom of $\mathrm{Naja}$ nigricollis. Biochim. Biophys. Acta 802: 49 .

Forbes, C., Turpie, A., Ferguson, J., McNicol, G. and Douglas, A. 1969. Effect of Gabon viper (Bitis gabonica) venom on blood coagulation, platelets and the fibrinolytic enzyme system. J. Clin. Pathol. 22: 312

Gasmi, A., Karoui, M., Benlasfar, Z., Karoui, H., El Ayeb, M. and Degalli, K. 1991. Purification and characterization of a fibrinogenase from Vipera lebetina (desert adder) venom. Toxicon 29 (7): 827-836.

Goa, K., Henwood, J., Stolz, J., Langley, M. and Clissold, S. 1990. Streptokinase: A revaluation of its terapeutic use in acute myocardial infarction. Drugs 39 (5): 693.

Gutiérrez, J. y Bolaños, R. 1980. El problema de los efectos hemorrágico y mionecrótico por mordedura de serpiente en el Continente Americano. Bol. Of. Sanit. Pan-am. 89: 149.

Gutiérrez, J., Cerdas, D., Arroyo, E., Lomonte, B. y Gene, J. 1982. Patogénesis y neutralización de los efectos locales inducidos por veneno de terciopelo (Bothrops asper). Acta med. Costarric. 25: 255.

Herzig, R., Ratnoff, O. and Shainoff, J. 1970. Studies on a procoagulant fraction of southern copperhead snakes venom: the preferential release of fibrinopeptide $B$. J. Lab. Clin. Med. 76: 451. 
Lowry, O.; Rosebrough, N.; Farr, A. and Randall, R. 1951. Protein measurement with the Folin phenol reagent. J. Biol. Chem. 193: 265-275.

Markland, F. 1988. Fibrin (ogen) olytic enzymes from snake venoms. In: Hemostasis and Animal Venoms. Pirkle and Markland (eds.). Marcell Dekker. New York.

Meneses, G. 1974. Ofidios y ofidismo en el Perú. II. Aspectos ecológicos de la fauna ofídica ponzoñosa. Inst. Rev. Zoonosis e Invest. Pecuar. 2 (3-4): 79 84.

Moran, J. and Geren, C. 1981. Characterization of a fibrinogenase from northem cooperhead (Agkistrodon contortrix mokasen) venom. Biochim. Biophys Acta 659: 161.

Ouyang, C. and Huang, T. 1979. a and bfibrinogenases from Trimeresurus gramineus snake venom. Biochim. Biophys. Acta 571: 270.

Ouyang, C., Teng, C. and Chen, Y. 1977. Physicochemical properties of a- and b-fibinogenases of Trimeresurus mucrosquamatus venom. Biochim. Biophys. Acta 481:622.

Solís, C., Escobar, E. y Yarlequé, A. 1999. Purificación y caracterización de L-amino ácido oxidasa del veneno de la serpiente Bothrops brazili “jergón shushupe”. Revista Peruana de Biología 6 (1): 75-84.
Takahashi, T. and Ohsaka, A. 1970. Purification and characterization of proteinase in the venom of Trimeresurus flavoviridis. Complet. separation of the enzymes from hemorrhagic activity. Biochim. Biophys. Acta 198 (2): 293-307.

Tanizaki, M., Zingali, R., Kawasaki, H., Imajoh, S., Yamazaki, S. and Suzuki, K. 1989. Purification and some characteristics of a $\mathrm{Zn}$-metalloproteinase from the venom of Bothrops jararaca (Jararaca). Toxicon $27(7): 747$.

Tillet, W. and Garner, R. 1933. The fibrinolytic activity of hemolytic stretococci. Journal of Experimental Medicine. 58: 485.

Warburg, O. and Christian, W. 1941. Isolierung and Kristallisation des Gärungsferments Enolase. Biochem. 2, 310: 384-421.

Weber, K. and Osborn, M. 1969. The realiability of molecular weight determinations by dodecil sulphate polyacrilamide gel electrophoresis. J. Biol. Chem. 244: 4406.

Zeballos, J., Escobar, E. y Yarlequé, A. 1999. Aislamiento y algunas propiedades de una fosfolipasa del veneno de la serpiente Bothrops brazili. Boletin de la Sociedad Quimica del Perú. Vol. LXV N. ${ }^{\circ}$ 1: 10-20. 